\title{
Cheek and tongue pressures in the molar areas and the atmospheric pressure in the palatal vault in young adults
}

\author{
Urs Thüer, Robert Sieber and Bengt Ingervall \\ Department of Orthodontics, University of Bern, Switzerland
}

SUMMARY The pressures acting on the maxillary and mandibular posterior teeth from the tongue and cheeks were measured in 24 adults aged 22-29 years. In addition, the pressure in the palatal vault was recorded.

The pressure at two maxillary (buccal and lingual) and two mandibular (buccal and lingual) measuring points, and in the palatal vault was recorded simultaneously. Repeated recordings of the pressures at rest, and during chewing and swallowing were made.

The pressures at rest were of similar magnitude (about $2 \mathrm{~g} / \mathrm{cm}^{2}$ ) at the buccal and lingual sides of the mandibular posterior teeth. The median resting pressure at the maxillary posterior teeth was $2.7 \mathrm{~g} / \mathrm{cm}^{2}$ on the buccal side and $1.0 \mathrm{~g} / \mathrm{cm}^{2}$ on the lingual side. The difference in the maxilla was significant, but not in the mandible. It was concluded that the equilibrium of tooth position is maintained by the pressure from the cheeks and the tongue.

During chewing and swallowing the pressures on the lingual side of the teeth were greater than those on the buccal side.

At rest about half of the subjects had a negative pressure at the palatal vault, but no correlations between the resting pressure at the palatal vault and the resting pressures on the teeth were found.

\section{Introduction}

The discussion on the equilibrium of the position of the teeth between forces from the soft tissues and periodontium is closely related to the aetiology of malocclusions and how much retention the patient will need after treatment (Jacobs, 1969). Weinstein et al. (1963) discussed the forces on the crown of a tooth from the surrounding soft tissues. They were of the opinion that the teeth may have more than one stable position and that even small forces, acting over a long time, cause tooth movement. Fifteen years later, Proffit (1978a,b) added more influencing factors to the equilibrium theory when he discussed the importance of the tongue and lips as sources of intrinsic forces, in contrast to extrinsic forces from habits or orthodontic appliances. Forces from the occlusion and from the periodontal membrane, also known as eruptive forces, were discussed by Proffit (1978a). The primary factors for the equilibrium are still the resting pressures of the tongue, lips and cheek, and possibly the forces created within the periodontal membrane. Proffit (1978a) found higher resting pressures from the tongue at the incisors and at the molars than from the surrounding soft tissues, whereas Hensel (1983) reported higher pressures from the soft tissues than from the tongue. The periodontal membrane plays an important role because periodontal breakdown results in destabilization of the equilibrium (Proffit, 1978b).

Most authors agree that measurements during functional exercises provide little information about the influence of the soft tissues on the position of the teeth (Weinstein et al., 1963; Luffingham, 1969a,b; Lear et al., 1972; Proffit, 1978a,b; Thüer et al., 1985; Lubit et al., 1990; Fröhlich et al., 1991; Horn et al., 1995). The normal soft tissue functions are of only short duration and, therefore, of little importance for tooth position. The position of the tongue at rest is, however, important for the position of the 
teeth (Proffit, 1978a). This is evident in subjects with mouth breathing or with enlarged tonsils (Linder-Aronson, 1970; Behlfelt, 1990).

The aim of most authors has been to measure with very precise instruments the lowest pressures at rest. This was especially difficult for the upper lip, where no pressure was often recorded (Proffit et al., 1964; Luffingham, 1968).

Negative pressures on the teeth were found in several of our earlier studies (Thüer et al., 1985; Thüer and Ingervall, 1986; Ingervall and Thüer, 1988; Fröhlich et al., 1991) and by several other authors (Fränkel, 1967; McNulty et al., 1968; Gould and Picton, 1975; Bookhold and Hensel, 1989; Shellhart et al., 1997). The explanations for these findings were mostly vague. Negative pressures are created inside the mouth during normal functioning of the soft tissues when the mouth is closed. Negative pressures also exist during speaking and eating (Thüer et al., 1985, 1999).

The cause of negative pressures in the space between the lips or cheeks and the teeth at rest is not clearly explained in the literature. If the soft tissues touch the teeth, positive pressures would be expected, but the soft tissues may not always be in contact with the teeth. One explanation could be a negative pressure inside the oral cavity that influences the open-ended measuring system used in our laboratory (Thüer et al., 1985). On the other hand, negative pressures have also been found with other measuring equipment, such as strain gauges (McNulty et al., 1968; Gould and Picton, 1975; Becker and Hensel, 1979; Bookhold and Hensel, 1989), and electronic miniature pressure transducers (Shellhart et al., 1997).

Negative pressures have been attributed to methodological errors (Shellhart et al., 1997), withdrawal of the soft tissues from the teeth (McNulty et al., 1968; Shellhart et al., 1997) and the need to swallow during the registration because of the water stream of the pressuremeasuring system (Halazonetis et al., 1994). Outward movement of the lips caused by gravity when the head is inclined forwards could also be a cause of negative pressures (Faigenblum, 1966; McNulty et al., 1968). A similar explanation was offered by Fränkel, who stated that negative pressures were produced when the mandible moved into the rest position with the mouth closed. This force can be strong enough to influence the morphogenesis of the dentoalveolar arch (Fränkel, 1967, 1980). Walpole Day and Foster (1970) stated that negative pressures, measured in the palatal vault, should be sealed by the tongue from the rest of the oral cavity. If the tongue has a pathologically low position, the negative pressures would also be measurable in the buccal fold.

Weinstein et al. (1983) described the human cheeks as fluid-filled, double elastic membrane systems. After a certain amount of displacement of the cheeks by the movement of an artificial tooth, a plateau was reached with a constant force over a distance of $0.5-1 \mathrm{~mm}$. The conclusion was that the measurements of the resting pressures have to be made within an area of $0-2 \mathrm{~mm}$ from the tooth surface, as also mentioned by Gould and Picton (1962) and Lear et al. (1965). With greater distances the pressures increase exponentially (Weinstein et al., 1983). There is constant debate as to whether pressures or forces should be measured. The lips can exert a fluid pressure on the pressure-measuring devices, so measurements should be made with pressure and not force-sensing devices (Lindeman and Moore, 1990). Lindeman and Moore (1990), and Shellhart et al. (1996) compared force and pressuremeasuring devices, and selected the Entran ${ }^{\circledR}$ EPL6 pressure transducer as the device with the highest degree of validity. The pressures recorded with the beam-type transducers were twice as high as the pressures yielded by the diaphragm transducers (Shellhart et al., 1996). The diaphragm pressure transducer measures pressures from more than one direction and can be positioned closer to the tooth surface than the load cells and beam-type transducers. This may explain the differences in the pressure values of various studies.

The main aim of the present investigation was to measure pressures at the lingual and buccal sides of the molar teeth simultaneously, and to explore the reasons for negative pressures found in earlier studies at the lingual and buccal locations of the teeth. A further aim was to study inter-relationships between pressures measured 


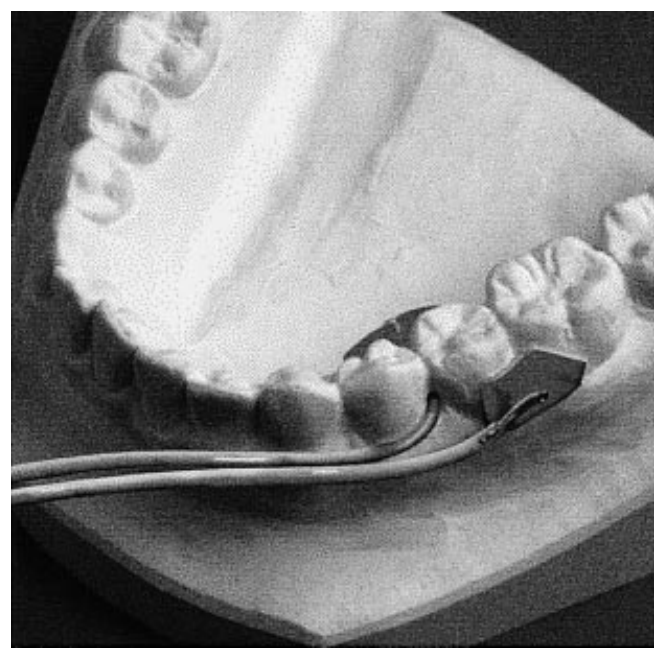

Figure 1 Mouthpieces for the measurement of the pressures in the mandible.

in the palate, and at the buccal and lingual measuring points.

\section{Subjects and methods}

Twenty-four dental students (12 men and 12 women) with a median age of 25 years 0 months (range 21 years 9 months-29 years 0 months) participated in the study. They all had acceptable occlusions; 16 had a perfect Class I, two had Class I with anterior crowding, two had Class I and an end-to-end relationship of the incisors, one had a tendency towards Class III, two were Class II division 1, and one Class II with upper anterior crowding. No subject had a posterior crossbite. Clinical examination revealed normal function of the lips, cheeks, and tongue at rest, during chewing and during swallowing.

Pressure measurements were made at five points simultaneously (Figures 1 and 2):

1. At the lingual inter-dental space between tooth 34 and 35 .

2. At the buccal inter-dental space between tooth 35 and 36 .

3. At the palatal inter-dental space between tooth 24 and 25

4. At the buccal inter-dental space between tooth 25 and 26 .

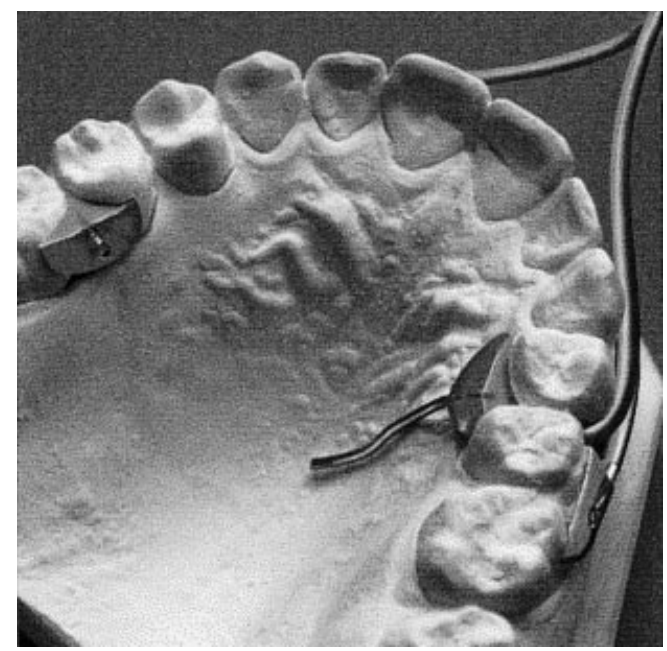

Figure 2 Mouthpieces for the measurement of the pressures in the maxilla.

5. From the palatal inter-dental space between tooth 15 and 16, a cannula was guided along the palatal mucosa to the highest point of the vault. The water escape at the end of the cannula could not be obstructed by the tongue. Therefore, pure atmospheric pressure was measured at this point.

Five polythene tubes (outer diameter $1.2 \mathrm{~mm}$ ) were guided from the external measuring apparatus through the oral rim to the mouthpieces, which were glued to the teeth. The measuring point was an open cannula that was embedded in an acrylic shield. The open end of the cannula was flush with the acrylic surface (Figure 3). At the palatal and lingual measuring points, the tubes were led through the inter-dental spaces, which kept the acrylic shield very thin with only minimal disturbance of the tongue. The same intra-oral set-up has been used in two earlier investigations (Fröhlich et al., 1992, 1993), where lingual pressures were measured. The acrylic shields to hold the tubes in place buccally were not used in the present study.

The extra-oral measuring system consisted of a bottle of water and compressed air, a pressure transducer and a flow-limiting valve. The pressure caused a small, constant stream of water to escape through the cannula. When this was 


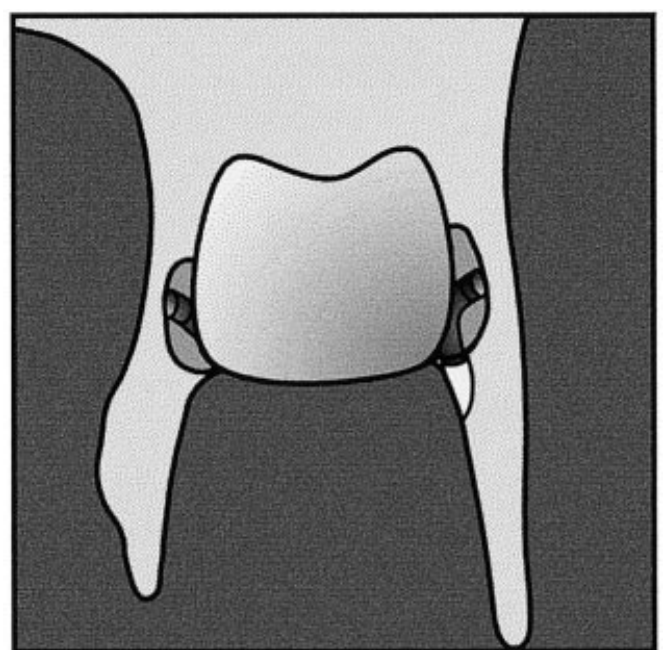

Figure 3 Schematic view of the measuring points for simultaneous measurements of cheek and tongue pressures on the molar teeth.

impeded by the soft tissues or sucked out by a negative air pressure, a varying pressure was built up in the water system, which was recorded by the transducer. This reflects the pressures from the soft tissues or the intra-oral air pressure. The water escaping through the cannula is swallowed by the person being tested. The pressure-measuring system is open to the oral cavity and it can therefore measure not only pressure exerted at the place of water escape, but also positive and negative air pressure inside the oral cavity. The principles of the pressuremeasuring system have been described in several articles (Thüer et al., 1985; Thüer and Ingervall, 1986, 1990; Ingervall and Thüer, 1988; Fröhlich et al., 1991, 1992). One additional channel was added to the set-up of Fröhlich et al. (1992, 1993) to enable measurement at five locations simultaneously.

Electromyographic recordings were made by fixing bipolar surface electrodes to the right anterior temporal muscle for the registration of the activity of this muscle. The recording of the muscle activity enabled evaluation of the state of rest, the chewing cycles and the act of swallowing (Fröhlich et al., 1991, 1992). The electromyographic signal of the temporal muscle was also displayed on an oscilloscope, which was placed in front of the subject. The subject could thus observe the activity of the muscle on the screen. This was especially useful for control of the muscle activity at rest. Care was taken not to influence the habitual rest position of the lips.

Measurements were made during the following activities:

(1) at rest, i.e. during the lowest electromyographic activity observed by the subject on the oscilloscope (biofeedback);

(2) during two acts of swallowing, on command, one teaspoonful $(5 \mathrm{ml})$ of water;

(3) during two acts of eating of one piece of Swedish crispbread (approximately $7 \mathrm{~cm}^{2}$ );

(4) repeated recording at rest.

The measurements were repeated after a median of 35 days (range 7-132 days, inter-quartile range 19.5 days).

\section{Analysis of the pressure recordings}

The five signals from the pressure transducers and the electromyographic signal were amplified and recorded on thermosensitive paper by a 15inch thermal array recorder (Gould ${ }^{\circledR}$ TA 4000, Gould, Ballainvillier, France). The recordings were analysed on the paper strip of the recorder. The pressure level at rest was measured when the recording showed a constant pressure level with simultaneous minimal activity of the temporal muscle during at least 5 seconds. The measurements of the pressure level during the two recordings at rest were averaged.

The maximal pressure during the four chewing cycles in the middle of each of the two acts of chewing was measured and averaged. The beginning and end of the chewing cycles, necessary for the measurements, were determined from the electromyogram of the anterior temporal muscle.

The maximal pressure during the two acts of swallowing of water was averaged.

\section{Statistical methods}

Systematic differences between repeated recordings were evaluated with Wilcoxon's matchedpairs, signed-ranks test. 
The standard deviation of the single measurement (accidental error, si) was calculated with the formula:

$$
s i=\sqrt{\frac{\sum d^{2}}{2 n}}
$$

in accordance with Dahlberg (1940). The accidental errors were generally high, as also found in earlier studies. The forces from the repeated recordings were therefore averaged for the further analysis, which reduced the errors by a factor of 0.7 .

The distribution of the variables was checked with Q-Q plots. Slight skewness was evident on some plots. Therefore, non-parametric statistical methods were used in the tests. The MannWhitney $U$-test was used to analyse differences between the sexes.

Differences between buccal and lingual pressures were tested with Wilcoxon's matchedpairs, signed-ranks test. Correlations between variables were evaluated with Spearman's rank correlation.

\section{Results}

\section{Reproducibility of the pressure recordings}

Systematic differences between the repeated recordings were found at the palatal vault and at the mandibular lingual measuring point at rest, during chewing and swallowing. The pressure at the mandibular lingual point was higher at the first than at the second recording, while the pressure at the palatal vault was higher at the second than at the first recording. The mean differences (in $\mathrm{g} / \mathrm{cm}^{2}$ ) between the two recordings at rest, and during chewing and swallowing, were $3.4,100.3$, and 100.3 , respectively, in the mandible, and $-3.8,-52.3$, and -90.6 in the palatal vault.

The accidental errors were in all recordings (at rest, and during chewing and swallowing) and in both jaws larger for the recordings on the lingual than on the buccal side of the teeth (Table 1). The difference was statistically significant. For all functions studied, the largest errors were noted in the mandibular lingual recording, followed by the recording in the palatal vault.

\section{Pressures acting on the teeth}

Only one variable differed significantly with sex. The swallowing pressure at the mandibular buccal measuring point in women was twice as high as the pressure in men $\left(99.1 \mathrm{~g} / \mathrm{cm}^{2}\right.$ versus $\left.49.0 \mathrm{~g} / \mathrm{cm}^{2}, 0.01<P<0.05\right)$. All other pressures were not significantly different. Therefore, both sexes were combined in all further tests.

It was possible to measure pressures at five points simultaneously and, therefore, to examine the pressure distribution inside the oral cavity at rest and during functional exercises (Table 2 and Figure 4). Figure 4a shows the distribution of the recording at the palatal vault to be positively skewed (the median being closer to the 25 th than

Table 1 Accidental errors of the method $(s i)$ in $\mathrm{g} / \mathrm{cm}^{2}$ for duplicate recordings of tongue and cheek pressures in 24 subjects.

\begin{tabular}{llll}
\hline & $\begin{array}{l}\text { Pressure in } \\
\text { rest position } \\
\text { si }\end{array}$ & $\begin{array}{l}\text { Maximal pressure } \\
\text { during chewing } \\
\text { si }\end{array}$ & $\begin{array}{l}\text { Maximal pressure } \\
\text { during swallowing } \\
\text { si }\end{array}$ \\
\hline Mandible lingual & 6.87 & 94.90 & 114.26 \\
2 Mandible buccal & 3.88 & 34.80 & 53.63 \\
3 Maxilla lingual & 4.15 & 32.42 & 83.28 \\
4 Maxilla buccal & 2.52 & 21.40 & 31.99 \\
5 Palatal vault & 4.66 & 52.35 & 100.65 \\
Significance of differences & $1-2^{* *}$ & $3-2^{* *}$ & $1-2^{* *}$ \\
& $3-4^{* *}$ & $3-4^{* *}$ & 3 \\
\hline
\end{tabular}

$* 0.01<P<0.05 ; * * 0.001<P<0.01$. 
Table 2 Median, mean, standard deviation, and range of variation of the pressures (in $\left.\mathrm{g} / \mathrm{cm}^{2}\right)$ acting on the posterior teeth at rest, and during chewing and swallowing and the air pressure at the palatal vault.

\begin{tabular}{|c|c|c|c|c|c|}
\hline & Median & Mean & SD & Range & $\begin{array}{l}\text { Number of individuals with } \\
\text { a negative pressure value }\end{array}$ \\
\hline \multicolumn{6}{|l|}{ Pressures in the rest position } \\
\hline 1 Mandible lingual & 2.41 & 2.22 & 3.34 & $-9.36-6.69$ & 5 \\
\hline 2 Mandible buccal & 2.01 & 2.49 & 3.01 & $-2.01-10.84$ & 5 \\
\hline 3 Maxilla lingual & 1.01 & 1.39 & 2.03 & $-1.74-5.89$ & 7 \\
\hline 4 Maxilla buccal & 2.68 & 2.67 & 1.93 & $-2.54-7.09$ & 1 \\
\hline 5 Palatal vault & -0.81 & 0.06 & 3.55 & $-5.50-9.12$ & 13 \\
\hline \multicolumn{6}{|l|}{ Significant differences between: $3-4^{*}$} \\
\hline \multicolumn{6}{|l|}{ Maximal pressures during chewing } \\
\hline 1 Mandible lingual & 73.84 & 81.80 & 55.91 & $14.27-238.97$ & \\
\hline 2 Mandible buccal & 30.38 & 33.11 & 25.31 & $5.55-124.19$ & \\
\hline 3 Maxilla lingual & 54.96 & 59.80 & 35.44 & $11.58-137.44$ & \\
\hline 4 Maxilla buccal & 31.89 & 35.30 & 18.41 & $13.42-82.06$ & \\
\hline 5 Palatal vault & 31.24 & 32.20 & 25.55 & $0.18-100.70$ & \\
\hline \multicolumn{6}{|l|}{ Significant differences between: $1-2 * *, 3-4 * * *$} \\
\hline \multicolumn{6}{|l|}{ Maximal pressures during swallowing } \\
\hline 1 Mandible lingual & 174.86 & 182.57 & 67.12 & $39.61-332.3$ & \\
\hline 2 Mandible buccal & 41.28 & 67.98 & 51.54 & $10.74-181.24$ & \\
\hline 3 Maxilla lingual & 187.28 & 195.95 & 62.40 & $65.79-315.49$ & \\
\hline 4 Maxilla buccal & 54.04 & 67.57 & 41.23 & $19.47-193.32$ & \\
\hline 5 Palatal vault & 84.92 & 89.40 & 56.21 & $7.39-217.49$ & \\
\hline Significant differences between: $1-2 * * *, 3-4 * * * *$ & & & & & \\
\hline
\end{tabular}

$* 0.01<P<0.05 ; * * 0.001<P<0.01 ; * * * P<0.001$.

to the 75th percentile). The same is true for the pressures recorded on the buccal side of the mandible and the maxilla during swallowing (Figure 4c).

The median pressures recorded at rest on the mandibular posterior teeth were of similar magnitude at the buccal and at the lingual sides (Table 2). In the maxilla, the pressures recorded at rest on the posterior teeth were smaller on the lingual than on the buccal side. The smallest pressure acting on the teeth at rest was found on the lingual side in the maxilla. The highest pressure was noted on the buccal side in the maxilla. The pressures recorded at the buccal and lingual sides in the individual subjects at rest are shown in Figure 5.

The pressures during chewing and swallowing were significantly greater on the lingual than on the buccal side in both the maxilla and the mandible. During chewing, the median maxillary lingual pressure was 2.2 times and the mandibular lingual pressure 3.7 times greater than the pressures measured on the buccal side of the teeth (calculated on an individual basis).

During swallowing, the median maxillary lingual pressure was 4.2 times and the mandibular lingual pressure 4.5 times greater than the pressure recorded on the buccal side (calculated on an individual basis).

\section{Pressures in the palatal vault and negative pressures}

A small negative median pressure was found at rest in the palatal vault (Table 2 and Figure $4 a$ ). Thirteen of the 24 subjects had a negative pressure at the palatal vault in the rest position (Figure 5, column c). Five had negative pressures at the mandibular lingual and buccal positions, seven at the maxillary lingual measuring point, and only one subject had a negative value at the maxillary buccal measuring point. Although 


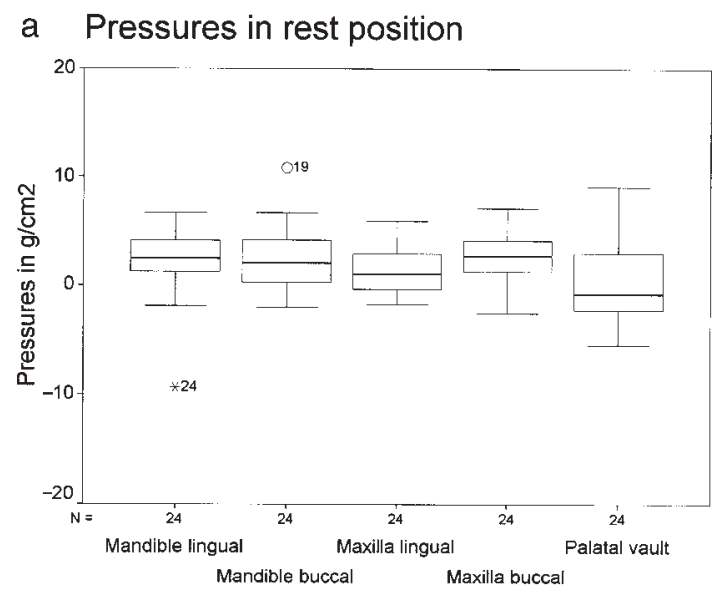

C Maximal pressures during swallowing

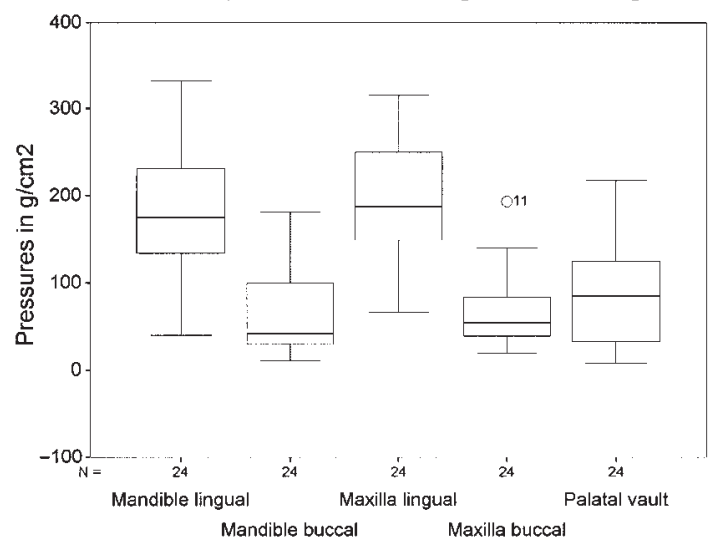

Figure 4 The box-plots show the distribution of the pressure values (a) in the rest position, (b) during chewing and (c) during swallowing. The lower boundary of the box is the 25th and the upper boundary is the 75th percentile. The horizontal line inside the box represents the median value. The largest and smallest values that are not outliers or extreme values are represented by the whiskers. Extreme values or outliers, more than 3 box-lengths from the upper or lower edge of the box, are marked with an asterisk. Cases with values between 1.5 and 3 box-lengths from the upper or lower edge of the box are marked with a circle.

the median pressure in the palatal vault at rest was slightly negative, in one subject a positive pressure of $9 \mathrm{~g} / \mathrm{cm}^{2}$ was recorded.

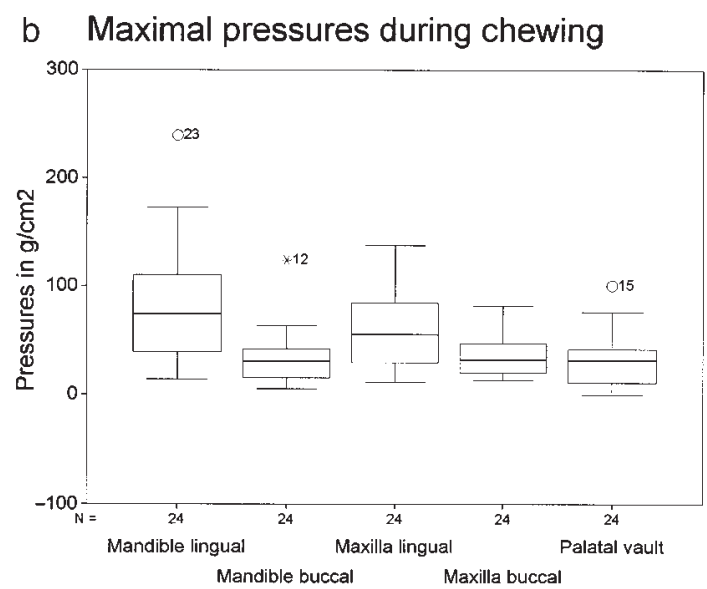

\section{Correlations}

Coefficients of correlation were only calculated between the pressures in the palatal vault and the other four locations. No significant correlations were found in the rest position. One significant correlation was found during chewing and one during swallowing. During chewing the pressure recorded at the maxillary buccal measuring point was positively correlated to the pressure measured in the palatal vault $(\mathrm{Rho}=0.50,0.01<P<0.05)$. During swallowing there was a negative correlation between the pressures at the mandibular buccal measuring point and the pressure in the palatal vault $(\mathrm{Rho}=-0.49,0.01<P<0.05)$.

\section{Discussion}

As in previous studies (Gould and Picton, 1964; Luffingham, 1968; Thüer et al., 1985; Fuhrimann et al., 1987; Ingervall and Thüer, 1988; Fröhlich et al., 1991, 1992, 1993), the accidental errors of the method were large. These errors are a combination of methodological inconsistencies and biological intra-individual variations (Luffingham, 1969a). The only way to minimize the errors is to make repeated observations, which, however, has practical limitations. It is believed that the pressures from the soft tissues on the teeth at rest are more important than the pressures exerted during functions such as chewing and swallowing. As mentioned in the 


\section{Pressures at rest}

a b

c

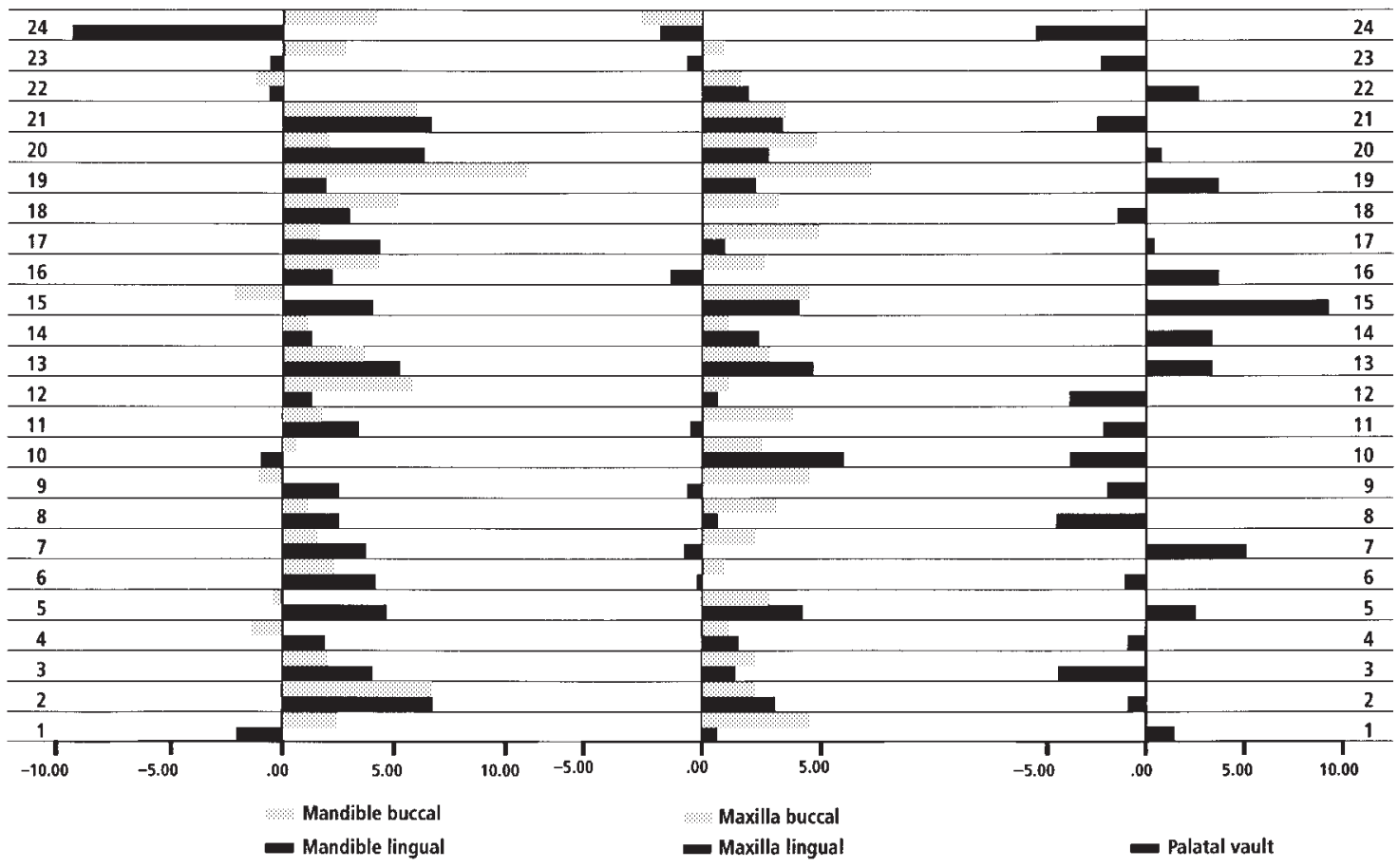

Figure 5 Median buccal and lingual individual pressures (a) in the mandible and (b) the maxilla, and pressures measured at (c) the palatal vault at rest.

introduction, the decisive factor is the duration of the pressure. In this study, the analysis of the resting pressures was based on four recordings, two on each of two occasions.

The most important result of this study was the finding that the pressure recorded on the buccal and lingual sides of the mandibular posterior teeth was of the same magnitude. As shown in Table 3, some authors have found considerably higher pressures on the lingual than on the buccal side in the mandible (Winders, 1962; Lear and Moorrees, 1969; Luffingham, 1969b). Only Hensel (1983) found smaller lingual than buccal pressures. The pressures reported by Proffit (1975) and Proffit et al. (1975) were of about the same magnitude, buccally and lingually, but considerably larger than those reported by practically all other authors. We believe that the inconsistent results are largely of a methodological nature. As mentioned in the introduction, the type of measuring device (diaphragm or beam), as well as the extension of the measuring device from the tooth surface, has a profound influence on the results. The high resting pressures reported by Proffit (1975) and Proffit et al. (1975) may be a consequence of the beam-type measuring device mounted on thick acrylic plates.

In the maxilla, the median buccal resting pressure was 2.7 times greater than the lingual pressure, in line with the proportions reported by Lear and Moorrees (1969). Luffingham (1969b) and Hensel (1983), on the other hand, found seven times greater buccal than lingual pressures. Again, these inconsistencies may be of a methodological nature. 
Table 3 Mean pressures at the buccal and lingual surfaces of the maxillary and mandibular posterior teeth at rest.

\begin{tabular}{|c|c|c|c|c|c|}
\hline & $\begin{array}{l}\text { Maxilla } \\
\text { buccal }\end{array}$ & $\begin{array}{l}\text { Maxilla } \\
\text { lingual }\end{array}$ & $\begin{array}{l}\text { Mandible } \\
\text { buccal }\end{array}$ & $\begin{array}{l}\text { Mandible } \\
\text { lingual }\end{array}$ & \\
\hline This study & 2.7 & 1.4 & 2.5 & 2.2 & Adults \\
\hline Winders, 1962 & 2.5 & 6.5 & 2.5 & 6.0 & Undefined age group \\
\hline Gould and Picton, 1964 & 7.2 & & 21.1 & & Adults \\
\hline Lear and Moorrees, 1969 & 1.0 & 0.4 & 0.4 & 1.2 & Adults \\
\hline Luffingham, 1969b & 6.8 & 0.1 & 1.0 & 5.0 & Young adults \\
\hline Proffit et al., 1975 & 8.9 & & 12.9 & 11.9 & Young adult aboriginals \\
\hline Proffit, 1975 & & & 17.0 & 22.5 & Young adult whites \\
\hline Hensel, 1983 & 6.9 & 1.0 & 5.9 & 3.3 & Young adults \\
\hline Ingervall and Thüer, 1988 & 3.3 & & & & Adults \\
\hline Fröhlich et al., 1991 & & -0.1 & & 4.9 & Adults \\
\hline Fröhlich et al., 1992 & & 0.2 & & 3.7 & Adults \\
\hline
\end{tabular}

In a review article, Proffit (1978b) described the different natural forces acting on the teeth and discussed their possible influence on tooth position. He stated that the forces acting on the lingual side of the teeth are greater than those on the buccal side and therefore suggested that additional, unknown, forces add up to the equilibrium of tooth position. Forces emanating from the periodontal membrane were specifically mentioned. The results of the present study, where the pressure was measured simultaneously on the buccal and lingual sides of the teeth, as well as the results reported by Hensel (1983), show, however, that the pressure acting on the lingual side of the teeth is not greater than the pressure on the buccal side. The pressures on the teeth from the tongue and from the surrounding soft tissues (cheeks and lips) are, therefore, sufficient to explain the equilibrium of tooth position. At least, this conclusion holds true for the mandibular posterior teeth. In this study, greater buccal than lingual resting pressures were found at the maxillary posterior teeth, but the difference was small.

During chewing, and even more during swallowing, the pressures on the lingual side of the teeth were greater than those on the buccal side. The greater lingual than buccal pressures during these functions are in line with the results of many authors (Winders, 1962; Lear et al., 1969; Luffingham, 1969a,b; Proffit and Norton, 1970; Gould and Picton, 1975; Proffit, 1978a,b).
Because of their short duration during the day and night, these pressures are, however, not believed to influence the position of the teeth (Proffit, 1978a,b). In addition, at least during chewing, the teeth are subject to greater forces from antagonistic tooth contact, which may act in a stabilizing way.

Approximately half of the subjects had a negative pressure in the palatal vault at rest. The existence of such pressure within the oral cavity was thus confirmed. The reason why a negative resting pressure was found in about 50 per cent of the individuals and not in the other 50 per cent is unclear. One possible explanation could be varying resting posture of the soft tissues and the tongue. No effort was made to standardize these postures because this would violate the habitual resting posture of the subject. As mentioned in the introduction, the influence from the soft tissues on the teeth should be regarded as a pressure. This makes it possible to compare the air pressure recorded in the palatal vault with the pressure measured on the teeth. However, no correlations were found between the resting pressures measured on the teeth and the pressure recorded in the palatal vault. The absence of correlations may be due to methodological imperfections. The great variations in the recording (partly of a biological nature) may obscure the relationship. It is therefore not possible to offer any definite explanation for the negative pressures occasionally found at the locations of 
the teeth. The negative correlation between the pressure in the palatal vault and the mandibular buccal pressure during swallowing illustrates that a negative pressure is built up in the oral cavity during part of the act of swallowing, possibly contributing to an increase in pressure on the buccal surfaces of the teeth. This explanation would be in line with the opinion of Fränkel (1967, 1980), and Walpole Day and Foster (1970) that a negative resting pressure in the palatal vault increases the pressure from the cheeks and lips on the teeth. However, their theory could not be confirmed by the pressures at rest in this study.

\section{Address for correspondence}

Dr Urs Thüer

Klinik für Kieferorthopädie

Freiburgstrasse 7

CH-3010 Bern

Switzerland

\section{Acknowledgements}

This study was supported by the Swiss Dental Association's Foundation for Research in Dentistry (Grant No. 173).

\section{References}

Becker W, Hensel S 1979 Methode zur Messung von Weichteildrücken in der Mundhöhle. Zahn- Mund- und Kieferheilkunde 67: 497-506

Behlfelt K 1990 Enlarged tonsils and the effect of tonsillectomy. Characteristics of the dentition and facial skeleton. Posture of the head, hyoid bone and tongue. Mode of breathing. Swedish Dental Journal, Supplement 72: $1-35$

Bookhold P, Hensel S 1989 Metrische Untersuchungen zum Weichteilverhalten am anterioren Zahnbogen bei regelrechter und progener Frontzahnstellung. ZahnMund- und Kieferheilkunde 77: 801-806

Dahlberg G 1940 Statistical methods for medical and biological students. Comparisons between materials. Chapter IX. George Allen \& Unwin Ltd, London

Faigenblum M J 1966 Negative oral pressures. Dental Practitioner 16: 214-216

Fränkel R 1967 Die Dynamik des interokklusalen Unterdrucks. Deutsche Zahnärztliche Zeitung 22: 1282

Fränkel R 1980 A functional approach to orofacial orthopaedics. British Journal of Orthodontics 7: 41-51
Fröhlich K, Thüer U, Ingervall B 1991 Pressure from the tongue on the teeth in young adults. Angle Orthodontist 61: 17-24

Fröhlich K, Ingervall B, Thüer U 1992 Further studies of the pressure from the tongue on the teeth in young adults. European Journal of Orthodontics 14: 229-239

Fröhlich K, Ingervall B, Schmokzer R 1993 Influence of surgical tongue reduction on pressure from the tongue on the teeth. Angle Orthodontist 63: 191-198

Fuhrimann S, Schüpbach A, Thüer U, Ingervall B 1987 Natural lip function in wind instrument players. European Journal of Orthodontics 9: 216-223

Gould M S E, Picton D C A 1962 A method of measuring forces acting on the teeth from the lips, cheeks and tongue. British Dental Journal 112: 235-242

Gould M S E, Picton D C A 1964 A study of pressures exerted by the lips and cheeks on the teeth of subjects with normal occlusion. Archives of Oral Biology 9: 469-478

Gould M S E, Picton D C A 1975 Sub-atmospheric pressures and forces recorded from the labio-buccal surfaces of teeth during swallowing in adult males. British Journal of Orthodontics 2: 121-125

Halazonetis D J, Katsavrias E, Spyropoulos M N 1994 Changes in cheek pressure following rapid maxillary expansion. European Journal of Orthodontics 16: 295-300

Hensel S 1983 Kopfhaltung und Weichteilfunktionexperimentelle Untersuchungen. Stomatologie der DDR 33: 249-259

Horn H, Göz G, Bacher M, Koch J, Axmann-Krcmar D 1995 Maximalkraftmessungen des Lippen- und Zungendrucks und ihre Bedeutung für die klinische Diagnostik orofazialer Dyskinesien. Fortschritte der Kieferorthopädie 56: $187-193$

Ingervall B, Thüer U 1988 Cheek pressure and head posture. Angle Orthodontist 58: 47-57

Jacobs R M 1969 Muscle equilibrium: fact or fancy. Angle Orthodontist 39: 11-21

Lear C S, Moorrees C F A 1969 Buccolingual muscle force and dental arch form. American Journal of Orthodontics 56: $379-393$

Lear C S C, Grossmann R C, Flanagan J B M, Moorrees C F A 1965 Measurement of lateral muscle forces on the dental arches. Archives of Oral Biology 10: 669-689

Lear C S C, Mackay J S, Lowe A A 1972 Threshold levels for displacement of human teeth in response to laterally directed forces. Journal of Dental Research 51: 1478-1482

Lindeman D E, Moore R N 1990 Measurement of intraoral muscle forces during functional exercises. American Journal of Orthodontics and Dentofacial Orthopedics 97: 289-300

Linder Aronson S 1970 Adenoids: their effect on mode of breathing and nasal airflow and their relationship to characteristics of the facial skeleton and the dentition. Acta Otolaryngologica Supplementum 265: 1-132

Lubit E C, Wallach M A, Schwalb R 1990 A study of the relationship of maximal perioral muscle pressure and 
tonic resting pressure using a pneumohydraulic capillary infusion system. Angle Orthodontist 60: 215-220

Luffingham J K 1968 Pressure exerted on teeth by the lips and cheeks. Dental Practitioner 19: 61-64

Luffingham J K 1969a Lip and cheek pressure exerted upon teeth in three adult groups with different occlusions. Archives of Oral Biology 14: 337-350

Luffingham J K 1969b Soft tissue pressure and dental arch form. Transactions of the European Orthodontic Society: pp. 313-328

McNulty E C, Lear C S, Moorrees C F A 1968 Variability in lip adaptation to changes in incisor position. Journal of Dental Research 47: 537-547

Proffit W R 1975 Muscle pressure and tooth position: North American whites and Australian aborigines. Angle Orthodontist 45: 1-11

Proffit W R 1978a Equilibrium theory revisited: factors influencing position of the teeth. Angle Orthodontist 48: 175-186

Proffit W R 1978b The facial musculature in its relation to the dental occlusion. In Carlson D S, McNamara, J A Jr (eds) Muscle adaptation in the craniofacial region. Monograph No. 8, Craniofacial Growth Series, Center for Human Growth and Development, University of Michigan, Ann Arbor, pp. 73-89

Proffit W R, Norton L A 1970 The tongue and oral morphology: influence of tongue activity during speech and swallowing. American Speech Hearing Association Reports 5: 106-115

Proffit W R, Kydd W L, Wilskie G H, Taylor D T 1964 Intraoral pressures in a young adult group. Journal of Dental Research 43: 555-562

Proffit W R, McGlone R E, Barrett M J 1975 Lip and tongue pressures related to dental arch and oral cavity size in Australian aborigines. Journal of Dental Research 54: $1161-1172$

Shellhart C W, Moawad M I, Paterson R L, Matheny J 1996 Lip adaptation to simulated dental arch expansion. Part 1: reliability and precision of two lip pressure measurement mechanisms. Angle Orthodontist 66: 249-254

Shellhart W C, Moawad M I, Matheny J, Paterson R L, Hicks E P 1997 A prospective study of lip adaptation during six months of simulated mandibular dental arch expansion. Angle Orthodontist 67: 47-54

Thüer U, Ingervall B 1986 Pressure from the lips on the teeth and malocclusion. American Journal of Orthodontics and Dentofacial Orthopedics 90: 234-242

Thüer U, Ingervall B 1990 Effect of muscle exercise with an oral screen on lip function. European Journal of Orthodontics 12: 198-208

Thüer U, Janson T, Ingervall B 1985 Application in children of a new method for the measurement of forces from the lips on the teeth. European Journal of Orthodontics 7: $63-78$

Thüer U, Grunder J, Ingervall B 1999 Pressures from the lips on the teeth during speech. Angle Orthodontist 69: 139-146

Walpole Day A J, Foster T D 1970 The measurement of variations in intraoral air pressure. Angle Orthodontist 40: $45-50$

Weinstein S, Haack D C, Morris L Y, Snyder B B, Attaway H E 1963 On an equilibrium theory of tooth position. Angle Orthodontist 33: 1-26

Weinstein S, Ho T P, Bowley W W, Boyle M 1983 Extensibility characteristics of the human cheek. Journal of Dental Research 62: 344-348

Winders R V 1962 Recent findings in myometric research. Angle Orthodontist 32: 38-43 